\title{
RESPON PERKECAMBAHAN BENIH SENGON LAUT (Paraserianthes falcataria (L.) Nielsen) TERHADAP ALELOPATI DAUN DAN RHIZOME ALANG-ALANG (Imperata cylindrica L.)
}

\section{RESPONSE OF SENGON LAUT (Paraserianthes falcataria (L.) Nielsen) SEED GERMINATION ON LEAVES AND RHIZOMES COGONGRASS (Imperata cylindrica L.) ALLELOPATHY}

\author{
Euis F. S. Pangemanan dan Semuel P. Ratag*) \\ "Program Studi Ilmu Kehutanan, Fakultas Pertanian Universitas Sam Ratulangi, Manado
}

\begin{abstract}
A plant species can release a toxic compound which can inhibit the growthof other plant species. The success of planting certain tree species, both inside and outside the forest area with agroforestry system can be affected by allelopathy of other plant species. The objective of this research was to study the response of sengon laut (Paraserianthes falcataria (L.) Nielsen) seed germination on cogongrass (Imperata cylindrica L.) leaves and rhizomes allelopathy. The experimental design was a randomized complete design with four replicates. The treatments were leaves and rhizomes extracts of cogongrass, and water as control. The results showed that the extract concentration of $20 \%$ (weight/volume), then the sengon laut seed germination was not affected by the extracts.
\end{abstract}

Keywords: sengon laut, cogongrass, allelopathy, seed germination

\section{ABSTRAK}

Suatu jenis tumbuhan dapat mengeluarkan senyawa bersifat toksik yang dapat menghambat pertumbuhan jenis tumbuhan lainnya. Keberhasilan penanaman jenis pohon tertentu, baik di dalam maupun di luar kawasan hutan dengan sistem agroforestri, dapat dipengaruhi oleh alelopati jenis tumbuhan lain. Penelitian ini bertujuan untuk mengkaji respon perkecambahan benih sengon laut (Paraserianthes falcataria (L.) Nielsen) terhadap alelopati daun dan rizome Alang-alang (Imperata cylindrica L.). Percobaan dilaksanakan dengan rancangan acak lengkap dengan empat ulangan. Perlakuan terdiri dari ekstrak daun dan rizome alang-alang serta air sebagai kontrol. Hasil penelitian menunjukkan bahwa dengan konsentrasi ekstrak sebesar $20 \%$ (berat/volume), maka perkecambahan benih sengon laut tidak dipengaruhi oleh alelopati dari ekstrak daun dan rizome alang-alang.

Kata kunci: sengon laut, alang-alang, alelopati, perkecambahan benih 


\section{PENDAHULUAN}

Dewasa ini upaya-upaya memperbaiki kondisi lingkungan hidup dan kesejahteraan manusia, baik di kawasan hutan maupun di luar kawasan hutan telah menjadi perhatian berbagai pihak, baik secara nasional maupun internasional. Penanaman pohon adalah salah satu kegiatan konservasi yang tidak hanya memperbaiki lingkungan secara fisik dan biologis, melainkan dapat pula meningkatkan pendapatan masyarakat.

Berkaitan dengan upaya meningkatkan tutupan vegetasi pohon, maka berbagai program telah dan akan dilaksanakan bersama antara pemerintah, swasta, masyarakat, Lembaga Swadaya Masyarakat (LSM), dan semua stakeholder yang peduli lingkungan. Pembuatan hutan tanaman di kawasan hutan dan lahan milik rakyat, reboisasi, dan penghijauan adalah kegiatan-kegiatan yang dimaksudkan untuk meningkatkan jumlah individu pohon.

Upaya pelestarian ekosistem hutan menghadapi berbagai tantangan, tidak hanya dilihat dari pertumbuhan pohon-pohon hasil reboisasi melainkan gangguan yang datang dari adanya jenis-jenis tumbuhan invasif seperti alang-alang. Ahli-ahli ekologi secara umum mengetahui bahwa tumbuhtumbuhan invasif dapat merubah keragaman dan komposisi komunitas-komunitas ekologi (Powell, et al., 2013; Pysek, et al., 2012) dan invasi-invasi sering dipandang sebagai satu dari beberapa penggerak utama perubahan ekosistem (Liao, et al., 2008, Simberloff, 2011; Mack, et al., 2000, Brooker, 2006; Ehrenfeld, 2010). Banyak tumbuhan invasif termasuk alang-alang yang pengaruhnya terhadap populasi-populasi tumbuhan dan komunitas kurang dimengerti (Hulme, et al., 2013). Dampak yang bisa diduga dari invasi alang-alang, termasuk mempengaruhi pada level komunitas terhadap diversitas dan pertumbuhan dan perkembangan tumbuhan (Brewer, 2008) dan pada level ekosistem terhadap siklus hara (Daneshgar dan Jose, 2009), gangguan (Platt dan Gottschalk, 2001), dan dekomposisi (Holly, et al., 2009).

Salah satu sistem yang dapat menjadi alternatif untuk meningkatkan jumlah pohon sekaligus merupakan upaya konservasi dan peningkatan pen- dapatan masyarakat adalah agroforestri (kombinasi kegiatan pertanian dan kehutanan). Agroforestri adalah sekumpulan nama untuk sistem dan teknologi penggunaan lahan dimana tanaman tahunan berkayu yang terdiri dari pohon, semak, palem, bambu, dan lain-lain, ditanam atau digunakan secara sengaja dalam satu unit pengelolaan lahan bersama-sama dengan tanaman pertanian dan/ atau hewan dalam beberapa bentuk pengaturan ruang dan rangkaian waktu. Dalam sistem ini terjadi hubungan timbal balik antara komponen-komponen ekologis dan ekonomi (Lundgren dan Raintree, 1982 dalam Nair, 1993). Salah satu interaksi ekologis yang bisa terjadi adalah penanaman pohon sengon laut pada lahan yang sebelumnya didominasi alang-alang. Interaksi yang terjadi dapat berupa kompetisi terhadap air, hara, cahaya, dan lain-lain. Selain itu dapat pula terjadi interaksi dimana salah satu jenis tanaman mengeluarkan senyawa bersifat toksik.

Untuk mencapai tujuan dan sasaran sistem agroforestri diperlukan informasi dalam rangka meminimumkan resiko kegagalan dan memaksimumkan hasil dalam konteks pembangunan berkelanjutan berwawasan lingkungan. Salah satu faktor yang perlu dipertimbangkan untuk mengoptimalisasikan jasa lingkungan dan produksi dalam pelaksanaan sistem agroforestri, yakni interaksi antara dua jenis tumbuhan dimana salah satu jenis mengeluarkan senyawa kimia yang bersifat toksik terhadap jenis lainnya. Interaksi ini menurut Wratten dan Fry (1980) ; Rice (1984) ; Putnam dan Tang (1986) disebut alelopati. Istilah alelopati pertama kali digunakan oleh Molisch pada tahun 1937 yang mendefinisikan semua pengaruh langsung atau tidak langsung dari substansi biokimia yang ditransfer kepada tanaman lainnya (Hibbs dan Shumaker, 1987; Cheng and Cheng, 2015). Rice (1984) menyatakan bahwa alelopati adalah pengaruh merugikan dan menguntungkan secara langsung dan tidak langsung dari satu tanaman (termasuk mikroorganisme) kepada tumbuhan lainnya melalui produksi senyawa kimia yang masuk ke dalam lingkungan. Senyawa alelopati atau alelokimia dikelompokkan dalam beberapa klas kimia yang tergolong pada asam-asam fenolik, alkaloid, terpenoid, flavonoid, asam lemak rantai panjang, 
lakton, dan senyawa-senyawa volatil lainnya (Xuan, et al. 2016).

Interaksi alelopati berbeda dengan kompetisi (misalnya air, mineral, cahaya, dan lain-lain) karena pengaruh alelopati tergantung pada bahan kimia alami yang ditambahkan bukan satu faktor yang berkurang dari lingkungan (Hibbs dan Shumaker, 1987). Fenomena biologis dari interaksi alelopati dimana satu organisme menghasilkan senyawa kimia yang mempengaruhi organisme lainnya pada proses-proses pertumbuhan, survival, perkembangan dan reproduksi. Interaksi alelopatik dapat menjadi salah satu dari sekian banyak faktor yang dapat mempengaruhi distribusi dan kelimpahan dalam komunitas tumbuhan dan pentingnya dalam proses suksesi tumbuh-tumbuhan invasif (Chou, 1999; Malik, 2003; Zheng, et al., 2015).

Keberhasilan pelaksanaan penanaman pohon dalam sistem agroforestri dapat dipengaruhi oleh adanya alelopati alang-alang (Imperata cylindrica), dimana kehadirannya dapat disebabkan karena lahan yang digunakan sebelumnya didominasi oleh alang-alang atau tumbuh bersama dengan tanaman-tanaman yang dikombinasikan pada lahan hutan yang baru dibuka. Beberapa bukti yang menunjukkan bahwa alang-alang bersifat alelopatik, antara lain yakni menghambat pertumbuhan ketimun (Rice, 1984), dan menghambat perkecambahan benih kedelai (Ratag, 1997). Eussen dan Neimann mengidentifikasi adanya $p$-coumaric acid, o-coumaric acid, gentisic acid, vanillic acid, $p$ hydroxybenzoic acid, vanillin, dan $p$ hydroxybenzaldehyde sebagai alelokimia yang terdapat pada material daun alang-alang (Putnam dan Tang, 1986), sedangkan Amartalingan mengidentifikasi adanya ferulic, vanillic, $p$-coumaric, dan syringic acid yang terdapat pada material rizome alang-alang (Putnam dan Tang, 1986).

Kandungan senyawa alelokimia dapat berbeda jumlahnya menurut organ-organ tanaman seperti batang, daun, bunga, serbuk sari, biji, buah, akar dan rhizome (Rice, 1984) dan berbeda dengan spesies lainnya dipengaruhi oleh faktor lingkungan seperti cahaya, ultraviolet, radiasi ionisasi, mineral, stress kekeringan, jamur, patogen, dan insekta (Qasem and Foy, 2001).
Sifat toksik dari senyawa alelopati tergantung pada konsentrasi dan jenis tumbuhan Whittaker (1975). Pendapat tersebut didukung oleh Ratag (1997) yang menyatakan bahwa respon satu tanaman terhadap senyawa alelopati ditentukan oleh jenis senyawa, konsentrasi senyawa, dan jenis tanaman yang meresponnya. Meskipun alang-alang memiliki senyawa toksik yang dapat menghambat pertumbuhan tanaman lainnya, namun sifat toksiknya terhadap perkecambahan benih pohon sengon laut (Paraserianthes falcataria) perlu diuji.

Penelitian ini bertujuan untuk mengetahui sejauh mana alelopati yang diperoleh dari ekstrak daun dan rizome alang-alang mempengaruhi perkecambahan benih pohon sengon laut.

\section{METODE PENELITIAN}

Penelitian ini dilaksanakan di Kelurahan Malalayang Dua, Kota Manado. Waktu pelaksanaan penelitian untuk uji daya kecambah adalah delapan hari yang dilakukan pada bulan November tahun 2016.

Bahan dan alat yang digunakan adalah benih sengon laut, daun dan rizome segar alangalang, air suling, kotak perkecambahan, tanah, pasir, gelas ukur, ember plastik, timbangan, ayakan, kertas saring, blender, hand sprayer, mortar, dan alat tulis menulis.

Penelitian ini menggunakan metode uji daya kecambah secara langsung dengan substrat pasir dan tanah dalam perbandingan 1:1. Benih sengon laut yang telah diseleksi dengan cara perendaman, ditanam pada kotak perkecambahan yang berisi tanah yang telah diayak dan pasir, masing-masing kotak ditanami 100 bij. Larutan ekstrak diperoleh dari daun dan rizome alang-alang segar, masing-masing sebanyak 100 gram, dihaluskan kemudian dicampur dengan air suling sebanyak $500 \mathrm{ml}$ atau konsentrasinya $20 \%$ (berat segar/volume). Setelah itu, larutan tersebut disaring dan digunakan untuk menyiram substrat perkecambahan yang telah ditanami benih sengon laut. Selama perkecambahan, keadaan substrat tetap dipertahankan dalam kondisi kapasitas lapang dengan menambahkan larutan ekstrak masingmasing perlakuan. 
Desain yang digunakan dalam penelitian ini adalah Rancangan Acak Lengkap (RAL). Jumlah perlakuan sebanyak tiga dan masingmasing perlakuan terdiri dari empat ulangan. Perlakuan yang dimaksud terdiri dari A) air suling (kontrol), B) ekstrak daun alang-alang, dan C) ekstrak rizome alang-alang.

Respons yang diamati adalah 1). Persentase perkecambahan, dihitung pada hari kedelapan setelah benih ditanam. Persentase perkecambahan diperoleh dari rasio antara jumlah benih yang berkecambah secara normal dengan jumlah benih yang ditanam dikalikan $100 \%$ (Sutopo, 1988) dan 2). Laju perkecambahan, diamati setiap hari dengan menghitung benih yang berkecambah sampai dengan hari terakhir. Perhitungannya menggunakan rumus Koefisien Perkecambahan (KP) menurut Copeland (1976) sebagai berikut :

$$
K P=\frac{(100)\left(A_{1}+A_{2}+\ldots .+A_{n}\right)}{\left(A_{1} T_{1}+A_{2} T_{2}+\ldots .+A_{n} T_{n}\right)}
$$

dimana

$A=$ jumlah benih yang berkecambah pada hari tertentu

$B=$ waktu yang berkorespondensi dengan $A$

$\mathrm{n}=$ jumlah hari pada perhitungan terkahir.

Data yang diperoleh, selanjutnya dianalisis dengan analisis varians atau sidik ragam. Bila berbeda nyata dilanjutkan dengan Uji Beda Nyata Terkecil (BNT).

\section{HASIL DAN PEMBAHASAN}

Hasil pengamatan yang dapat dilihat pada Tabel 1, menunjukkan bahwa secara visual daya kecambah benih sengon laut tertinggi adalah perlakuan ekstrak rizome dengan nilai rataan $68,01 \%$ dan terendah adalah perlakuan ekstrak daun dengan nilai rataan $59,14 \%$. Perlakuan yang menghasilkan nilai daya kecambah tertinggi menunjukkan bahwa pengaruh alelopati paling sedikit pengaruhnya terhadap perkecambahan benih sengon laut, sebaliknya nilai terendah berarti pengaruh alelopati paling menekan perkecambahan benih sengon laut dibandingkan dengan kontrol.

Secara statistik, hasil analisis varians menunjukkan bahwa perlakuan ekstrak daun dan rizome alang-alang dengan konsentrasi $20 \%$ (berat segar/volume) tidak berbeda nyata bila dibandingkan dengan kontrol. Hal ini berarti bahwa pada konsentrasi ekstrak yang diberikan tersebut, alelopati alang-alang tidak berpengaruh negatif atau sebaliknya berpengaruh positif terhadap daya kecambah benih sengon laut.

Laju perkecambahan secara visual menunjukkan bahwa nilai tertinggi dihasilkan oleh perlakuan ekstrak rizome dengan nilai rataan 27,22 dan terendah dihasilkan perlakuan ekstrak daun. Secara statistik, sama halnya dengan parameter daya kecambah maka hasil analisis varians (Anova) terhadap parameter laju perkecambahan menunjukkan bahwa perlakuan ekstrak daun dan rizome alang-alang dengan konsentrasi $20 \%$ (berat segar/ volume) tidak berbeda nyata bila dibandingkan dengan kontrol. Hal ini berarti bahwa alelopati alang-alang tidak menekan atau menghambat laju perkecambahan benih sengon laut.

Bila kita membandingkan hasil penelitian ini dengan hasil-hasil penelitian tentang alelopati alang-alang sebelumnya, misalnya pertumbuhan ketimun (Rice, 1984), serta hasil identifikasi Eussen dan Niemann yang menunjukkan adanya beberapa senyawa alelokimia dalam material daun, $p$ coumaric acid, o-coumaric acid, gentisic acid, vanillic acid, $p$-hydroxybenzoic acid, vanillin, dan $p$ hydroxybenzaldehyde dan hasil identifikasi Amartalingan yang menunjukkan adanya beberapa senyawa alelokimia, yaitu ferulic, vanillic, $p$ coumaric, dan syringic acid dalam material rizome alang-alang (Putnam dan Tang, 1986), maka tidak berpengaruhnya ekstrak daun dan rizome alangalang terhadap perkecambahan benih sengon laut (baik positif maupun negatif) disebabkan oleh berbagai kemungkinan terkait jenis senyawa kimia, konsentrasi, dan respon adaptasi dari kecambah sengon laut. Pertumbuhan kecambah sengon laut yang mampu mentolerir pengaruh toksik dari alangalang atau senyawa alelokimia yang terdapat pada alang-alang belum bersifat toksik terhadap perkecambahan benih sengon laut pada konsentrasi yang digunakan dalam penelitian ini. Bila jumlah daun dan rizome alang-alang ditambah atau konsentrasi ekstrak diperbesar hingga jumlah tertentu, kemungkinan yang akan terjadi adalah pengaruh positif atau negatif. 
Tabel 1. Pengaruh Alelopati Alang-alang terhadap Persentase Perkecambahan Benih Sengon Laut

Table 1. The Allelophaty Effect of Cogongrass on the Seed Germination Percentage of Sengon Laut

\begin{tabular}{lc}
\hline \multicolumn{1}{c}{ Perlakuan } & Rataan Persentase Perkecambahan (\%) \\
\hline Kontrol (A) & 67,23 \\
Ekstrak daun (B) & 59,14 \\
Ekstrak rizome (C) & 68,01 \\
\hline
\end{tabular}

Tabel 2. Pengaruh Alelopati Alang-alang terhadap Laju Perkecambahan Benih Sengon Laut

Table 2. The Allelopathy Effect of Cogongrass on the Germination Rate of Sengon Laut Seed

\begin{tabular}{lc}
\hline \multicolumn{1}{c}{ Perlakuan } & Rataan Laju Perkecambahan \\
\hline Kontrol (A) & 27,04 \\
Ekstrak daun (B) & 26,17 \\
Ekstrak rizome (C) & 27,22 \\
\hline
\end{tabular}

Alelopati dari satu jenis tumbuhan tidak hanya berpengaruh negatif, melainkan dapat pula berpengaruh positif. Hasil penelitian Ratag (1997) menunjukkan bahwa ekstrak daun pinus dapat merangsang berat kering kecambah tanaman kedelai sebesar $16,25 \%$ dan panjang akar primer sebesar $16,72 \%$, membuktikan bahwa alelopati tumbuhan tertentu dapat berdampak positif bagi pertumbuhan tumbuhan lain. Penghambatan terhadap tumbuhan lainnya oleh alang-alang diteliti oleh Yanti, et al. (2016), dimana alelopati alang-alang menghambat pertumbuhan semai akasia (Acacia auriculiformis), mangium (A. mangium), dan akasia putih (A. alba).

Dalam hal ini pengaruh senyawa toksik dipengaruhi oleh konsentrasi ekstrak yang digunakan dan perbedaan jenis tumbuhan yang merespon. Kenyataan tersebut didukung oleh pendapat Whittaker (1975) bahwa sifat toksik dari senyawa alelokimia tergantung pada konsentrasi dan jenis tumbuhan. Khoiruddin, et al. (2012) menyatakan bahwa alang-alang dapat dimanfaatkan sebagai herbisida untuk menekan pertumbuhan biji gulma dalam tanah tergantung pada dosis ekstrak yang digunakan. Suatu senyawa bisa dikatakan termasuk alelopati tergantung pada banyak hal, termasuk fitotoksisitas dalam tanah dan jumlah yang dihasilkan oleh suatu tumbuhan (Hiradate, 2006; Hiradate, et al., 2010).

Hasil penelitian ini perlu diikuti dengan percobaan yang menggunakan konsentrasi lebih besar, residu dalam tanah, dan percobaan di lapangan untuk mendapatkan bukti yang bisa di- rekomendasikan untuk pelaksanaan agroforestri yang menggunakan tanaman sengon laut pada lahan yang sebelumnya didominasi alang-alang. Bukti alelopati biasanya agak sukar untuk dibuktikan. Hasil yang diperoleh di laboratorium bisa berbeda dengan di lapangan. Faktor-faktor biotik dan abiotik yang ada di lapangan sulit untuk diduplikasi di laboratorium dalam memperbanyak atau mengurangi alelopati (Duke, 2015).

Berdasarkan hasil penelitian ini dan penelitian-penelitian lainnya maka tumbuhan alangalang yang selama ini dipandang sebagai gulma ternyata tidak selalu menghambat pertumbuhan lainnya dalam interaksi kompetisi dan interaksi alelopati. Alang-alang dapat kita manfaatkan dalam peningkatan produksi pertanian, termasuk di dalamnya pengelolaan gulma dan penyakit. Beberapa allelokima dapat berperan sebagai penghambat pertumbuhan sedangkan yang lain dapat mendukung pertumbuhan tanaman. Penelitian Xuan, et al. (2016) membuktikan bahwa Ageratum conyzoides yang tergolong gulma ternyata bisa menjadi insektisida, anti jamur, dan herbisida serta mendukung pertumbuhan tanaman jeruk yang ditumpangsarikan dengan $\mathrm{A}$. conyzoides.

\section{KESIMPULAN}

Ekstrak daun alang-alang dengan konsentrasi $20 \%$ (berat segar/volume) tidak berpengaruh menghambat perkecambahan benih sengon laut. 
Ekstrak rizome alang-alang dengan konsentrasi $20 \%$ (berat segar/volume) tidak berpengaruh menghambat perkecambahan benih sengon laut.

\section{DAFTAR PUSTAKA}

Brewer, S. 2008. Declines in Plant Species Richness and Endemic Plant Species in Longleaf Pine Savannas Invaded by Imperata cylindrica. Biol. Invasions 10. Pp. 1257-1264.

Brooker, R.W. 2006. Plant-plant Interactions and Environmental Change. New Phytol. 171. pp. 271-284.

Cheng, F. and Z. Cheng. 2015. Research Progress on the Use of Plant Allelopathy in Agriculture and the Physiological and Ecological Mechanisms of Allelopathy. Front Plant Sci. 2015, Vol. 6; 1020.

Chou, C.H. 1999. Roles of Allelopathy in Plant Biodiversity and Sustainable Agriculture. Crit. Rev. Plant Sci. 18, pp. 609-636.

Daneshgar, P. and S. Jose. 2009. Imperata cylindrica, an Alien Invasive Grass, Maintains Control Over Nitrogen Availability in an Establishing Pine Forest. Plant Soil 320. pp. 209-218.

Duke, S.O. 2015. Proving Allelopathy in Crop-Weed Interactions. Weed Science 63 (Special Issue). pp. 121-132.

Ehrenfeld, J.G. 2010. Ecosystem Consequences of Biological Invasions. In: D.J. Futuyuma, H.B. Shafer, and D. Simberloff (Eds.). Annual Review of Ecology, Evolution, and Systematics. Vol. 41. pp. 59-80.

Hibbs, T. and C.A. Shumaker. 1987. The American Biology Teacher. Vol. 49 (1). pp 27-30.
Hiradate, S. 2006. Isolation Strategies for Finding Bioactive Compounds: Specific Activity vs Total Activity. Am. Chem. Soc. Symp. Ser. 927. pp. 113-126.

Hiradate, S., K. Ohsa, A. Furubayashi, and Y. Fujii. 2010. Quantitative Evaluation of Allelopathic Potentials in Soils: Total Activity Approach. Weed Sci. 58. pp. 258264.

Holly, D.C., G.N. Ervin, C.R. Jackson, S.V. Diehl, and G.T. Kirker. 2009. Effect of Invasive Grass on Ambient Rates of Decomposition and Microbial Community Structure: a Search for Causality. Biol. Invasions. 11. pp. 1855-1868.

Hulme, P.E., P. Pysek, V. Jarosik, J. Pergl, U. Schaffner, and M. Vila. 2013. Bias and Error in Understanding Plant Invasion Impacts. Trends Eco. Evol. 28. pp. 212218.

Khoiruddin, M. 2012. Pemanfaatan Ekstrak Alangalang (Imperata cylindrica L.) Sebagai Herbisida Pra Tumbuh. Agrium Vol. 17 (2). pp. 144-147.

Liao, C., R. Peng, Y. Luo, X. Zhou, X. Wu, C. Fang, J. Chen, and B. Li. 2008. Altered Ecosystem Carbon and Nitrogen Cycles by Plant Invasion: a Meta Analysis. Biol. Invasions 15. pp. 1713-1724.

Lundgren, B.O. and J. B. Raintree. 1982. Sustained Agroforestry. In: P.K.R. Nair. 1993. An Introduction to Agroforestry. Kluwer Academic Public in Cooperation with International Center for Research in Agroforestry, Dordrecht, Netherlands.

Mack, R.N., D. Simberloff, W.M. Lonsdale, H. Evans, M. Clout, and F.A. Bazzaz. 2000. Biotic Invasions: Causes, Epidemiology, Global Consequences, and Control. Ecology Appl. 10. pp. 689-710. 
Malik, A.U. 2003. Conifer Regeneration Problems in Boreal and Temperate Forests with Ericaceous Understory: Role of Disturbance, Seedbed Limitation, and Keystone Species Change. Crit. Rev. Plant. Sci. 22, pp. 341-366.

Nair, P.K.R. 1993. An Introduction to Agroforestry. Kluwer Academic Publisher-ICRAF, Netherlands.

Platt, W.J. and R.M. Gottschalk. 2001. Effects of Exotic Grasses on Potential Fine Fuel Loads in the Groundcover of South Florida Slash Pine Savannas. Int. J. Wildland Fire. 10. pp. 155-159.

Powell, K.I., J.M. Chase, and T.M. Knight. 2013. Invasive Plants Have Scale-dependent Effect on Diversity by Altering SpeciesArea Relationship. Science 339. pp 316318.

Putnam, A.R. and C.S. Tang. 1986. The Sciences of Allelopathy. John Wiley \& Sons. Canada.

Pysek, P., V. Jarosik, P.E. Hulme, J. Pergl, M. Hejda, U. Schaffner, and M. Vila. 2012. A Global Assesment of Invasive Plant Impacts on Resident Species, Communities, and Ecosystems: The Interaction of Impact Measures, Invading Species Traits and Environment. Global Change Biology 18. pp. 1725-1737.

Qasem, J.R. and C.L. Foy. 2001. Weed Allelopathy, its Ecological Impact and Future Prospects: a Review. J. Crop Prod. 4. pp. 43-119.
Ratag, S.P. 1997. Pengaruh Ekstrak Daun Pinus (Pinus merkusii), Gamal (Gliricidia maculata), dan Alang-alang (Imperata cylindrica) Terhadap Perkecambahan Benih Kedelai (Glycine max). Eugenia Vol. 3 No. 4, Tahun XIII. pp. 193-197

Rice, E.L. 1984. Allelopathy. Academic Press. Florida.

Simberloff, D. 2011. How Common are Invasioninduced Ecosystem Impacts? Biol. Invasions 13. pp. 1255-1268.

Whittaker, R.H. 1975. Communities and Ecosystem. Macmillan Publ. Co. New York.

Wratten, D.S. and G.L.A. Fry. 1980. Field an Laboratory Exercises in Ecology. Edward Arnold. London.

Xuan, T.D., L.H. Anh, D.T. Khang, P.T. Tuyen, T.N. Minh, T.D. Khanh, and K.H. Trung. 2016. Weed Allelochemicals and Possibility for Pest Management. International Letters of Natural Sciences Vol. 56. pp. 25-39.

Zheng, Y.L., Y.L. Feng, L.K. Zheng, R.M. Callaway, A. Valiente-Banuet, and D.Q. Luo. 2015. Integrating Novel Weapons and Evolutionarily Increased Competitive Ability in Success of Tropical Invader. New Phytol. 205, pp. 1350-1359. 